\title{
Targeting HER2 amplifications in gastric cancer
}

\author{
This article was published in the following Dove Press journal: \\ Gastrointestinal Cancer:Targets and Therapy \\ 31 January 2014 \\ Number of times this article has been viewed
}

\section{Lawson Ung \\ Terence C Chua \\ Neil D Merrett}

Department of Surgery, South Western Sydney Upper GI Surgical

Unit, Bankstown Hospital, University of Western Sydney, Sydney, NSW, Australia
Correspondence: Neil D Merrett Department of Surgery, Bankstown Hospital, University of Western Sydney, Sydney, NSW 2200, Australia Emailn.merrett@uws.edu.au
Abstract: While multimodality treatments, including neoadjuvant and adjuvant chemotherapy or chemoradiation, have become the global standard of care in patients with locally advanced and metastatic gastric cancers (GCs), long-term outcomes for patients remain poor. This reflects the aggressive tumor biology of GCs and occult nature of the disease, often presenting in its advanced stages, as well as the challenges of developing effective targeted therapy to treat this disease. The Trastuzumab for Gastric Cancer trial demonstrates that the addition of human epidermal growth factor 2 (HER2) monoclonal antibody trastuzumab to standard chemotherapy regimen consisting of 5-fluorouracil (5-FU) or capecitabine with cisplatin results in significant improvement in overall and progression-free survival. Although questions remain regarding the best methods by which to determine HER2 mutation positivity and amplification, through immunohistochemistry or in situ hybridization, and whether trastuzumab is effective for locally advanced, nonmetastatic GC in an adjuvant setting, the trial has led to a surge of clinical trials investigating the potential role of other HER2- and non-HER2-targeted therapies to improve patient outcomes. This review will discuss our current understanding of GC pathogenesis, current available treatments, and the potential impact that targeting HER2 amplifications may have in our efforts to individualize and optimize cancer care in GC individuals.

Keywords: Personalized cancer therapy, surgical oncology, gastrectomy, adjuvant treatment, targeted therapies

\section{Introduction}

Gastric cancer (GC) is a significant health problem, with an estimated 989,600 new diagnoses and 738,000 deaths per annum, according to the latest global data. ${ }^{1}$ While its total incidence is declining, particularly with the identification of Helicobacter pylori as a major risk factor, it still remains the second leading cause of cancer-related mortality in the world. ${ }^{2}$ For patients who present with, or progress to, metastatic gastric or gastroesophageal cancer (mGC), the long-term outlook is grim. ${ }^{3}$ Studies of its natural history place median survival from 3-5 months with supportive care alone, and from 7.5-12 months in patients receiving a range of traditional treatment modalities, including fluoropyrimidine-based and/or platinum-based chemotherapy, with or without radiotherapy and palliative surgery. ${ }^{3}$ In view of such a poor prognosis despite multidisciplinary oncological efforts, new treatments are urgently needed to improve patient outcomes, particularly in the setting of advanced disease.

One particularly encouraging advance in cancer care has been the development of biological agents that act on specific receptor or genomic targets within tumor cells to inhibit tumorigenesis and tumor progression. Based on the results of the recent international randomized clinical trial, the Trastuzumab for Gastric Cancer (ToGA) study, 
the monoclonal antibody trastuzumab (Herceptin ${ }^{\circledR}$; Roche, Basel, Switzerland) was recently approved by the European Medicines Agency, the US Food and Drug Administration (FDA), and the National Comprehensive Cancer Network for use in addition to standard chemotherapy for patients with mGCs with positive expression of human epidermal growth factor receptor 2 (HER2 [also Erb-2]). The HER2 receptor belongs to the epidermal growth factor (EGF) receptor (EGFR) family of tyrosine kinase receptors expressed by a variety of tumor cell lines that appear to drive tumorigenic pathways, including proliferation, invasion, adhesion, and metastatic spread. ${ }^{4,5}$ While it has been most extensively studied in the context of breast cancer, there is mounting evidence supporting the important prognostic and predictive role of HER2 status in GC, particularly in the selection of candidates with advanced, unresectable disease who may respond to HER2targeted therapy. This article will provide a brief overview of current accepted practice in the management of GC, introduce the HER2 receptor and the therapeutic applications of HER2 testing, and discuss the possible future role of HER2 in improving the prognosis for this deadly disease.

\section{Pathophysiology of GC}

An elegant model of gastric carcinogenesis was proposed by Correa who, in 1991, hypothesized GC to be the result of a sequence of events, starting with chronic gastritis and progressing from chronic gastritis to gastric atrophy, intestinal metaplasia, dysplasia and eventually to carcinoma. ${ }^{6}$ The underlying pathogenesis of GC occurs through a series of genetic mutations that lead to the loss of function of vital tumor suppressor or DNA repair mechanisms within gastric epithelial cells. As a result, cancerous cells acquire malignant characteristics, including the ability to proliferate independent of external signaling and the ability to induce new blood vessels (neovascularization) and to form metastases. ${ }^{7}$ The exact mechanisms behind tumor pathogenesis are still poorly understood, but are thought to stem from a chronic inflammatory process arising from multiple risk factors, including H. pylori infection, peptic ulcer disease, diet (particularly with regards to excess salt, nitrate, and nitrate consumption), pernicious anemia, and exposure to ionizing radiation. ${ }^{8}$

While there are conflicting data regarding many of these risk factors, evidence of a causative link between $H$. pylori infection and GC is certainly the strongest. It is estimated that H. pylori infection accounts for over $80 \%$ of GCs. ${ }^{9}$ Huang et $\mathrm{l}^{10}$ conducted a recent systematic review and meta-analysis investigating this relationship in 19 studies with 2,491 patients and 3,959 non-infected controls, demonstrating an odds ratio of 1.92 (95\% confidence interval [CI]: 1.32-2.24) of developing GC in patients infected with $H$. pylori. This result was consistent with a landmark Japanese study that prospectively studied 1,526 patients with duodenal or gastric ulcers, gastric hyperplasia, or non-ulcer dyspepsia, of whom 1,246 were infected with $H$. pylori, assessed by means of histological examination, rapid urease test, and serology. The study found that GC arose in 36\% of those infected and $0 \%$ of uninfected patients after a mean follow-up of 7.8 years. ${ }^{11}$ Patients with severe gastric atrophy, corpus-predominant gastritis, and/or intestinal metaplasia were at highest risk of developing both intestinal-type and diffuse-type GC. ${ }^{11}$ The link between $H$. pylori and GC was supported by a major retrospective study by the Taiwan Health Insurance Database of 80,255 patients with peptic ulcer disease treated by $H$. pylori eradication therapy. Analysis showed that the risk of GC developing in those who received early eradication dropped from 1.60 (95\% CI: $1.37-1.82)$ after $3-4$ years to $1.05(95 \%$ CI: $0.81-1.30$ ) after $7-10$ years. ${ }^{12}$

The study of the relationship between $H$. pylori infection and GC suggests that chronic inflammation may have a critical role in its pathogenesis. Briefly, part of the innate and adaptive immune response to $H$. pylori is the migration of an inflammatory infiltrate consisting of polymorphonuclear cells, macrophages, and lymphocytes to the gastric mucosa in an attempt to clear infection; in $H$. pylori infection, however, host responses are inadequate because, without active treatment, chronic infection persists throughout life and results in chronic gastritis, ulceration, and/or cancer. ${ }^{13}$ The resultant release of proinflammatory cytokines by immune cells and local tissues, including interleukin (IL)-1, IL-6, IL-8, tumor necrosis factor alpha, and interferon gamma, has several effects. Firstly, reactive oxygen species are released by recruited cells that trigger oxidative stress to the gastric epithelium and therefore result in DNA damage. Consequently, genomic alterations may lead to the inactivation of prominent tumor suppressor and mismatch repair genes such as p53 and DNA mismatch repair gene human mutL homolog 1 ( $h M L H 1),{ }^{14}$ increased rate of mitosis with genetic errors, and progression to adenocarcinoma. Secondly, it has been recently discovered that the inflammatory response appears to attract circulating bone marrow-derived stem cells (BMDCs), which represent the ideal uncommitted stem cell that may undergo malignant transformation. ${ }^{9}$ Murine-based experiments of BMDC engraftment into the gastric mucosa have shown that, in chronically infected mice, BMDCs may undergo metaplastic change (for example, through the expression of intestinal-type mucins) and progress onto dysplasia and carcinoma. ${ }^{9,15}$ 


\section{Current treatment options for GC}

The most important prognostic factor for patients with GC remains the tumor, nodes, and metastases (TNM) classification staging system described by the American Joint Committee on Cancer and the International Union Against Cancer. This system has a major influence on the management of GC, as it determines surgical resectability and use of adjunct or biological therapies based on the depth of tumor invasion, invasion of lymph nodes, and the presence of distant metastases.

In patients with early, localized stage 0 (TisN0M0) and stage 1A (T1N0M0) disease, surgery alone is considered to be curative in over $90 \%$ of patients, according to American and Japanese studies, ${ }^{16,17}$ however, the majority of Western patients with GC present with later, locally advanced disease (stage IB-IV), for which recurrences are commonly experienced following surgical resection. The high risk of disease relapse even after complete macroscopic (R0) resection may be attributed to the presence of occult micrometastatic disease that cannot be treated by surgical means alone. For this reason, there is now universal consensus that a multimodal strategy consisting of surgery with neoadjuvant and/or adjuvant chemotherapy or chemoradiation improves outcomes, although there are significant variations in the type of adjuvant therapy used globally. While adjuvant chemoradiation and chemotherapy are the standards in North America and Asia, respectively, neoadjuvant chemotherapy is considered the mainstay of treatment across Europe, the UK, and Australasia.

\section{Adjuvant chemoradiotherapy}

Following the publication of the South-West Oncology Group-Directed Intergroup Study 0116 (INT-0116) in 2001, adjuvant chemoradiotherapy gastrectomy has been considered the standard of care for patients with locally advanced GC in many Western centers, particularly in North America. This Phase III randomized controlled study enrolled 559 patients with stage IB-IV GC, of whom 277 were assigned surgery only and 282 received adjuvant chemoradiotherapy. The adjuvant therapy consisted of 5-fluorouracil (5-FU) 400-425 $\mathrm{mg} / \mathrm{m}^{2} /$ day and leucovorin $20 \mathrm{mg} / \mathrm{m}^{2} /$ day before, during, and after radiation to the tumor bed, regional nodes, and surgical anastomoses to a total dose of $45 \mathrm{~Gy}$. After a median follow-up of 10 years, this study found a statistically significant improvement in patients treated with adjuvant therapy (median survival 36 months versus 27 months, $P=0.0046) .{ }^{18}$

While these results were consistent with those acquired from an earlier report that demonstrated similar survival benefits after a 5-year median follow-up, ${ }^{19}$ the results of this trial were confounded by several factors. Firstly, out of the 559 enrolled patients, only $199(36 \%)$ and 54 (10\%) received D1 and D2 lymph node dissections, respectively, with the remaining 54\% receiving D0 gastrectomy. The majority of patients did not receive $\mathrm{D} 1+/ \mathrm{D} 2$ surgical resection, which is now generally considered necessary to achieve local control and long-term survival. It could therefore be argued that the study overestimated the effect of its chemoradiotherapy regime because the majority of patients enrolled in the study had received suboptimal surgery for which adjuvant treatment could compensate.

The therapeutic benefit of adjuvant chemoradiotherapy was recently evaluated by the Adjuvant Chemoradiation Therapy in Stomach Cancer (ARTIST) trial, based in South Korea, in which patients receiving D2 lymph node dissections were randomized to capecitabine plus cisplatin or capecitabine plus cisplatin and radiotherapy. ${ }^{20}$ The ARTIST trial had a higher completion rate than the INT-0116 trial (75\% compared to $64 \%$ ), possibly reflecting more accurate sophisticated radiotherapeutic targeting, and fewer adverse effects following radiotherapy. The ARTIST trial demonstrated no statistically significant differences in 3-year disease-free survival between the radiotherapy and non-radiotherapy arms $(78.2 \%$ versus $74.2 \%, P=0.0862$ ). While part of this negative finding may be attributed to the 269 patients with stage IB/II disease enrolled in the trial, it nonetheless supports the hypothesis that D2 resection alone confers adequate locoregional control without the need for radiotherapy.

\section{Neoadjuvant chemotherapy}

Across Europe and the UK, neoadjuvant chemotherapy has become the mainstay of treatment for patients with resectable stage II-III GC. This preference is based on the results of the Medical Research Council Adjuvant Gastric Infusional Chemotherapy (MAGIC) trial (MRC-ST02), a randomized controlled trial involving 503 patients with stage II or III resectable adenocarcinoma of the stomach (74\%), gastroesophageal junction (15\%), or lower esophagus (11\%). Patients were randomized to surgery alone or surgery with pre- and postoperative regimes consisting of intravenous (IV) epirubicin $50 \mathrm{mg} / \mathrm{m}^{2}$ and cisplatin $60 \mathrm{mg} / \mathrm{m}^{2}$ on day 1 , combined with continuous IV 5-FU $200 \mathrm{mg} / \mathrm{m}^{2}$ for 21 days. At a median follow-up of minimum 47 months, the group receiving surgery with perioperative chemotherapy were shown to have a greater likelihood of overall (hazard ratio [HR] 0.75, 95\% CI: $0.59-0.93, P=0.008$ ) and progression-free survival (HR $0.66,95 \%$ CI: $0.53-0.81, P<0.001)$, with similar morbidity and mortality outcomes. ${ }^{21}$ The projected 5-year survival of these two groups was $36 \%$ and $23 \%$, respectively. ${ }^{21}$ 
The MAGIC trial had several limitations. Firstly, its inclusion of patients with lower esophageal adenocarcinoma may have obscured the true effect of the chemotherapy regime for GCs because the study was powered adequately only to show survival benefits for the whole cohort, and not for individual subgroups. There were issues with patient compliance, with only $42 \%$ of patients completing their therapy protocol, and $34 \%$ of patients who completed preoperative chemotherapy did not commence postoperative therapy. Furthermore, while $38 \%$ of enrolled patients received D2 dissection, more than in INT-0116, it may still be argued that the survival benefit in patients treated with neoadjuvant chemotherapy could be expected in patients who had had suboptimal resections, particularly given that $33 \%$ of enrolled patients had noncurative surgery.

Despite these limitations, the findings of the MAGIC trial were supported by a smaller trial conducted in France by the Fédération Nationale des Centres de Lutte contre le Cancer (FNCLCC) and Fédération Francophone de Cancérologie Digestive (FFCD) groups, who investigated the effect of perioperative chemotherapy on 224 patients with adenocarcinoma of the stomach, esophago-gastric junction (EGJ), and lower esophagus. Patients were randomized to surgery alone or surgery with perioperative chemotherapy consisting of two to three preoperative cycles of IV cisplatin $\left(100 \mathrm{mg} / \mathrm{m}^{2}\right)$ on day 1 , plus 5 continuous days of IV 5 -FU ( $800 \mathrm{mg} / \mathrm{m}^{2} /$ day) for 5 days every 28 days, combined with three to four postoperative cycles of the same regimen. At a median follow-up of 68.4 months, it was shown that the neoadjuvant group experienced improved overall (5-year survival $38 \%$ compared to $24 \%$ in the control; HR $0.69,95 \%$ CI: $0.50-0.95, P=0.02$ ) and disease-free (5-year disease-free survival $34 \%$ compared to $19 \%$ in the control group; HR $0.65,95 \%$ CI: $0.48-0.89, P=0.003$ ) survival. ${ }^{22}$

Together with the results of the MAGIC trial, it appears that neoadjuvant chemotherapy resulted in similar survival outcomes to adjuvant chemoradiation as implemented by INT-0116. However, one should be wary of directly comparing these trials because, unlike the MAGIC and FNCLCC/ FFCD trials, randomization in INT-0116 was completed 20-40 days post-surgery, which may have facilitated the selection of fitter patients who had not demonstrated evidence of early disease recurrence or suffered operative morbidity. Nonetheless, the MAGIC and FNCLCC/FFCD studies continue to cast doubt on the therapeutic necessity of adjuvant radiotherapy with its uncertain survival benefit, side effect profile, and potential impact on patient compliance with postoperative chemotherapy.

\section{Adjuvant chemotherapy}

In Asia, adjuvant chemotherapy with D2 gastrectomy is the current standard of care for stage II-III GCs, based largely on the results of two large randomized controlled trials: the Adjuvant Chemotherapy for Gastric Cancer with S-1, an Oral Fluoropyrimidine (ACTS-GC) trial, ${ }^{23}$ based in Japan, and the Capecitabine and Oxaliplatin Adjuvant Study in Stomach Cancer ([CLASSIC] NCT00411229), ${ }^{24}$ based in South Korea, People's Republic of China, and Taiwan.

The ACTS-GC study was a randomized controlled study of 1,059 patients treated between 2001 and 2004 for stage II/III GC. Patients were randomly assigned D2 gastrectomy either alone or in combination with the orally administered $\mathrm{S}-1$, which is a combination of three drugs: tegafur, a 5-FU prodrug; gimeracil, a dihydropyrimidine dehydrogenase inhibitor; and oteracil, which inhibits the phosphorylation of 5-FU in the gut and reduces gastrointestinal toxicity. ${ }^{23}$ The trial was ceased 1 year after patient recruitment was completed, owing to an interim analysis that demonstrated statistically significant improvements in the overall $(P<0.001)$ and relapse-free survival $(P<0.001)$ of eligible patients receiving additional S- $1 .{ }^{23}$ With a median follow-up of 34.8 months, the 3-year overall survival rate for the group treated with adjuvant S-1 was $80.1 \%$, compared to $70.1 \%$ in the surgery-only group. Compared to the surgery-only group, the HR for death in the S-1 cohort was $0.68(95 \%$ CI: $0.52-0.87, P=0.003$ ).

The CLASSIC trial investigated the use of postoperative oxaliplatin and capecitabine for stage II-IIIb GC, in which 1,035 patients who underwent curative $\mathrm{D} 2$ gastrectomy were assigned follow-up only, or eight 3-weekly cycles of chemotherapy. In patients randomized to adjuvant chemotherapy, the regimen consisted of oral capecitabine $\left(1,000 \mathrm{mg} / \mathrm{m}^{2}\right.$ twice daily (bd) on days $1-14)$ with IV oxaliplatin $\left(130 \mathrm{mg} / \mathrm{m}^{2}\right.$ on day 1$)$. At a median follow-up of a minimum 34.2 months, the study found a 3-year survival of $74 \%$ in the adjuvant chemotherapy group, compared to $59 \%$ in those randomized to curative surgery only (HR 0.56, 95\% CI: 0.44-0.72, $P<0.0001){ }^{24}$

Unlike the trimodal treatments used in the INT-0116 (adjuvant chemoradiation) and MAGIC studies (pre- and postoperative chemotherapy), the results of the ACTS-GC and CLASSIC trials appear to suggest that a bimodal approach consisting of D1+/D2 gastrectomy with adjuvant chemotherapy may provide a comparable survival benefit. Differences in surgical and oncological practice, however, as well as trial protocol, may be accounted for by geographical variations. In Asia, patients with advanced GC are more likely to be diagnosed at an earlier stage due to population-based screening programs. ${ }^{25}$ Furthermore, D2 dissections are considered the 
current standard of care in Asia, but whether they confer a survival advantage over D0/D1 dissections remains a contentious issue among Western surgeons. Certainly, it could be argued that a third treatment modality was necessary in the INT-1116 and MAGIC trials in order to compensate for the low percentage of patients who received D2 dissections. Moreover, these major Asian studies (ACTS-GC and CLASSIC trials) exclusively recruited patients with $\mathrm{GC}$, while both INT-0116 and MAGIC also included adenocarcinomas of the lower esophagus in order to enhance patient recruitment. It is known that the tumor biology of lower esophageal cancers and GCs are distinct: due to a lack of protective serosa and rich lymphatic drainage, esophageal tumors are more likely to present early with locally advanced and metastatic disease. Thus one should be wary of directly comparing the results of these trials due to their methodological differences.

Several randomized controlled trials are currently under way to address several key issues left by these aforementioned studies, including the questionable role of radiotherapy and neoadjuvant chemotherapy in resectable stage II/III GC. The Docetaxel+Oxaliplatin+S-1 (DOS) Regimen as Neoadjuvant Chemotherapy in Advanced Gastric Cancer (PRODIGY) trial (NCT01515748) aims to randomize 640 patients to investigate the effect of neoadjuvant docetaxel, oxaliplatin, and S-1 assigning all patients to with or without neoadjuvant therapy with docetaxel, oxaliplatin and S1 followed up D2 gastrectomy and S1 adjuvant chemotherapy. Similarly, the Randomized Phase III Trial of Adjuvant Chemotherapy or Chemoradiotherapy in Resectable Gastric Cancer (CRITICS) trial (NCT00407186) has been designed to evaluate the addition of radiotherapy to a baseline treatment regime consisting of cisplatin and capecitabine to D2 surgery. The publication of these results will shed further light on the therapeutic indications of radiotherapy and neoadjuvant therapy and may introduce new standards of care in the treatment of GC.

\section{Chemotherapy for stage IV mGC}

Stage IV GC (mGC) is generally considered incurable and surgery is limited to palliation and relief of symptoms. Chemotherapy is the mainstay of treatment, supported by a recent Cochrane systematic review and meta-analysis of 35 trials, which showed the clinical efficacy of combination chemotherapy, either 5-FU/cisplatin \pm anthracyclines irinotecan-based or docetaxel-based regimens in advanced GC. ${ }^{3}$ In patients given systemic chemotherapy, the median survival range was 7.5-12 months.

Owing to concerns regarding patient tolerability, a number of randomized controlled trials have compared patient outcomes and toxicity of several widely used regimens. The results of a South Korean trial that compared capecitabine/ cisplatin with 5-FU/cisplatin as first-line therapy showed that the oral prodrug capecitabine was not inferior to 5-FU (median overall survival 10.5 months versus 9.3 months, $P=0.008$ ), was similarly well tolerated, and did not result in an increase in grade $3 / 4$ adverse events. ${ }^{26} \mathrm{~A}$ subsequent trial by Cunningham et al compared the outcomes of 1,002 patients who were randomized to four triplet regimes according to a two-by-two design: epirubicin and cisplatin with 5-FU or capecitabine, or epirubicin and oxaliplatin with 5-FU or capecitabine (ISRCTN51678883). ${ }^{27}$ While progressionfree survival and response rates did not differ significantly between regimens, it appeared that patients on oxaliplatin experienced significantly less grade $3 / 4$ neutropenia and thromboembolism, with modest increases in grade $3 / 4$ peripheral neuropathy and oxaliplatin. ${ }^{27}$

For HER2-positive advanced GC or mGC, trastuzumab, a recombinant, humanized monoclonal antibody against the HER2 receptor, has been recently approved by the European Medicines Agency, the FDA, and the National Comprehensive Cancer Network for use in combination chemotherapy, based on the results of the ToGA trial, in which trastuzumab was shown to improve survival outcome up to 16 months for strongly HER2-positive tumors (see the ToGA Trial). ${ }^{4}$

\section{The HER2 receptor and its prognostic role in GC EGFRs and the HER2 oncogene}

Traditionally, attempts to personalize cancer care for patients with GC have been anchored in considerations of tumor staging and patient comorbidities; however, the last decade has seen significant developments in our understanding of molecular biology of gastric cancer where specific cellular targets may be selectively modulated to inhibit tumor progression. Since the 1980s, the EGFR (or ErbB) family of transmembrane tyrosine-kinase receptors has been proposed as a key driver of tumorigenesis after an abnormal variant of the EGFR was discovered in the avian erythroblastosis tumor virus. ${ }^{28}$ The EGFR family consists of four members: HER1 (or EGFR), HER2 (p185, HER2/neu, or ErbB2), HER3 (ErbB3), and HER4 (ErbB4), all of which share a similar structure, comprising an extracellular ligand-binding domain, a transmembrane domain, and an intracellular cytoplasmic domain with tyrosine kinase activity (the latter with the exception of HER3). Under normal circumstances, the EGFR family is critical in mediating responses to cell-to-cell interactions, including mitosis and organogenesis. The binding of EGFR ligands, known as EGF-related peptide growth factors, to the extracellular domain of EGFRs is thought to induce 
their homodimerization and/or heterodimerization. This dimerization is critical in activating downstream cascades, starting with the phosphorylation of tyrosine residues, which ultimately affects gene expression downstream. ${ }^{29}$

The HER2 receptor member of the EGFR family is a 185 $\mathrm{kDa}$ protein encoded by chromosome $17 \mathrm{q} 21$. While it shares a similar molecular structure to other EGFRs, there is no known single ligand that binds to HER2 with strong affinity. Instead, the postulated role of HER2 in carcinogenesis is thought to be through spontaneous dimerization and constitutive activation of its tyrosine kinase, promoting cellular proliferation and mitogenic pathways. ${ }^{28,29}$ Additionally, the simultaneous over-amplification of HER2 with other members of the EGFR family, in particular, HER1 and HER3, may indicate that HER2 is the preferred heterodimerization partner for members of the EGFR family and may potentiate their effects in an autocrine fashion, leading to malignant proliferation independent of external growth of inhibitory signals. HER2 over-amplification has been most intensely studied in the context of breast cancer, believed to be present in approximately $20 \%-30 \%$ of invasive ductal carcinomas, ${ }^{25}$ however, it has also been implicated in a variety of other cancers, including pancreatic, colorectal, and gastric tumors. ${ }^{30}$

\section{HER2 prevalence in GC or gastroesophageal junction cancer}

The most common ways to analyze HER2 study involve immunohistochemistry (IHC) and fluorescence in situ hybridization (FISH) (Tables 1 and 2, respectively). The first study to document the potential role of HER2 in GC was in 1986 by Sakai et al, who conducted a comparative immunohistochemical study using a murine monoclonal antibody on both normal human gastric mucosae and advanced GC. The study found that, in normal mucosae, positive staining was observed only on parietal cells, compared to nine of $15(60 \%)$ GC tissues demonstrating IHC positivity. ${ }^{31}$ Despite differences in the specimens used, disease stage of the patient, and limits used to determine overexpression, it is generally thought that overexpression of HER2 occurs in 10\%-30\% of GC specimens (Table 1). This result is consistent with a recent systematic review by Chua and Merrett, which found a median overexpression rate of $18 \%$ in 49 studies, totaling 11,337 patients. $^{2}$ The results in Table 2 , which shows a number of FISH- or chromogenic in situ hybridization-based studies, similarly demonstrate over-amplification in $10 \%-30 \%$ of GC specimens. By far the most important and largest study of overexpression or over-amplification was the screening of potentially eligible patients for enrollment in the ToGA study conducted by Bang et al. ${ }^{4}$ Tumor specimens were considered to have overexpression/over-amplification of HER2 if they scored $3+$ on IHC, IHC 2+/FISH+, or FISH+. As a result, $22.1 \%$ of the 3,665 screened patients were considered to have HER2-positive disease.

\section{HER2 expression as a prognostic factor}

It is currently unclear whether HER2 over-amplification and/or overexpression are prognostic factors related to poorer overall survival. As Tables 2 and 3 demonstrate, several studies have

Table I Literature survey of studies evaluating HER2 overexpression in gastric cancer by immunohistochemical analysis, $\mathrm{n}>$ I00

\begin{tabular}{|c|c|c|c|c|c|c|c|c|}
\hline \multirow[t]{2}{*}{ Study } & \multirow[t]{2}{*}{$\mathbf{n}$} & \multirow{2}{*}{$\begin{array}{l}\text { Country } \\
\text { or region }\end{array}$} & \multirow[t]{2}{*}{ Sample } & \multicolumn{2}{|c|}{ TNM stage (n) } & \multirow{2}{*}{$\begin{array}{l}\text { Limit in } \\
\text { defining } \\
\text { mutation } \\
\text { positivity }\end{array}$} & \multirow{2}{*}{$\begin{array}{l}\text { Overexpression } \\
\text { (\%) }\end{array}$} & \multirow[t]{2}{*}{ Prognostic? } \\
\hline & & & & $\overline{I / I I}$ & III/IV & & & \\
\hline Kim et $\mathrm{al}^{32}$ & 1,475 & South Korea & Biopsy, surgical & NS & NS & $2+/ 3+$ & 26.8 & NS \\
\hline Yan et $\mathrm{al}^{5}$ & 128 & Singapore & Surgical & NS & NS & $3+$ & 9.4 & NS \\
\hline Marx et $\mathrm{al}^{33}$ & 166 & Germany & Surgical & 76 & 90 & $1+/ 2+/ 3+$ & 19 & NS \\
\hline Hofmann et $\mathrm{al}^{34}$ & 168 & $\begin{array}{l}\text { Germany, People's } \\
\text { Republic of China, } \\
\text { and Mexico }\end{array}$ & Surgical & NS & NS & $3+$ & 10.7 & NS \\
\hline Kim et $\mathrm{al}^{35}$ & 248 & South Korea & Surgical & 154 & 94 & $2+/ 3+$ & 22.6 & $\begin{array}{l}\text { Not } \\
\text { prognostic }\end{array}$ \\
\hline Park et $\mathrm{al}^{36}$ & 182 & South Korea & Surgical & 123 & 69 & $2+/ 3+$ & 15.9 & $\begin{array}{l}\text { Yes - poorer } \\
\text { survival }\end{array}$ \\
\hline Yano et $\mathrm{al}^{37}$ & 200 & Japan & Biopsy, surgical & 97 & 103 & $2+/ 3+$ & 23.0 & NS \\
\hline Allgayer et $\mathrm{al}^{38}$ & 203 & Germany & Surgical & 85 & 118 & $\mathrm{I}+/ 2+/ 3+$ & 91.6 & $\begin{array}{l}\text { Yes - poorer } \\
\text { survival }\end{array}$ \\
\hline Nakajima et al $^{39}$ & 128 & Japan & Surgical & NS & NS & $\begin{array}{l}>5 \% \\
\text { tumor cells }\end{array}$ & 16.4 & $\begin{array}{l}\text { Yes - poorer } \\
\text { survival }\end{array}$ \\
\hline Ishikawa et al ${ }^{40}$ & 375 & Japan & Surgical & NS & NS & $1+/ 2+/ 3+$ & 10.4 & NS \\
\hline
\end{tabular}

Abbreviations: HER2, human epidermal growth factor receptor 2; NS, not stated; TNM, tumor, nodes, metastases. 
Table 2 Literature survey of over-amplification of HER2 in gastric cancer by studies using in-situ hybridization, $\mathrm{n}>\mathrm{I00}$

\begin{tabular}{|c|c|c|c|c|c|c|c|c|c|}
\hline \multirow[t]{2}{*}{ Study } & \multirow[t]{2}{*}{$\mathbf{n}$} & \multirow{2}{*}{$\begin{array}{l}\text { Country } \\
\text { or region }\end{array}$} & \multirow[t]{2}{*}{ Sample } & \multicolumn{2}{|c|}{ TNM stage (n) } & \multirow[t]{2}{*}{ Method } & \multirow[t]{2}{*}{ Limit } & \multirow{2}{*}{$\begin{array}{l}\text { Amplification } \\
\text { (\%) }\end{array}$} & \multirow[t]{2}{*}{ Prognostic? } \\
\hline & & & & $\mathrm{I} / \mathrm{II}$ & III/IV & & & & \\
\hline $\begin{array}{l}\text { Kim } \\
\text { et al }{ }^{32}\end{array}$ & $\mathrm{I}, 475$ & South Korea & $\begin{array}{l}\text { Biopsy, } \\
\text { surgical }\end{array}$ & NS & NS & $\mathrm{FISH}$ & HER2:CEP-I $7 \geq 2$ & 10.8 & NS \\
\hline $\begin{array}{l}\text { Yan } \\
\text { et al }\end{array}$ & 128 & Singapore & Surgical & NS & NS & $\begin{array}{l}\mathrm{CISH} / \\
\mathrm{FISH}\end{array}$ & $\begin{array}{l}\text { HER2:CEP-I } 7 \geq 2.2 \\
\text { or }>5 \text { clusters } \\
\text { in }>50 \% \text { of cells }\end{array}$ & 11.7 & NS \\
\hline $\begin{array}{l}\text { Marx } \\
\text { et } \mathrm{al}^{33}\end{array}$ & 166 & Germany & Surgical & 76 & 90 & FISH & $\begin{array}{l}\mathrm{FISH}+\text { or } \\
\text { TOP2A:CEP-I7 } \geq 2\end{array}$ & 16.0 & $\begin{array}{l}\text { Not } \\
\text { prognostic }\end{array}$ \\
\hline $\begin{array}{l}\text { Hofmann } \\
\text { et } \mathrm{al}^{34}\end{array}$ & 168 & $\begin{array}{l}\text { Germany, People's } \\
\text { Republic of China, } \\
\text { and Mexico }\end{array}$ & Surgical & NS & NS & $\mathrm{FISH}$ & HER2:CEP-I $7 \geq 2.2$ & 17.4 & NS \\
\hline $\begin{array}{l}\text { Lordick } \\
\text { et a }\left.\right|^{41}\end{array}$ & 1,425 & Europe & $\begin{array}{l}\text { Biopsy, } \\
\text { surgical }\end{array}$ & NS & NS & $\begin{array}{l}\mathrm{FISH} / \\
\mathrm{IHC}\end{array}$ & NS & 22.3 & NS \\
\hline $\begin{array}{l}\text { Bang } \\
\text { et al }{ }^{4}\end{array}$ & 3,665 & International & $\begin{array}{l}\text { Biopsy, } \\
\text { surgical }\end{array}$ & NS & NS & $\begin{array}{l}\mathrm{FISH} / \\
\mathrm{IHC}\end{array}$ & $\begin{array}{l}\text { HER2:CEP-I } 17 \geq 2 \\
\text { or IHC } 3+\end{array}$ & 22.1 & NS \\
\hline $\begin{array}{l}\text { Kim } \\
\text { et } \mathrm{al}^{35}\end{array}$ & 248 & South Korea & Surgical & 154 & 94 & FISH & HER2:CEP-I7 $\geq 2$ & 7.7 & $\begin{array}{l}\text { Not } \\
\text { prognostic }\end{array}$ \\
\hline $\begin{array}{l}\text { Yano } \\
\text { et } \mathrm{al}^{37}\end{array}$ & 200 & Japan & $\begin{array}{l}\text { Biopsy, } \\
\text { surgical }\end{array}$ & 97 & 103 & FISH & HER2:CEP- $17 \geq 2$ & 27.1 & NS \\
\hline $\begin{array}{l}\text { Park } \\
\text { et } \mathrm{al}^{36}\end{array}$ & 182 & South Korea & Surgical & 123 & 69 & $\begin{array}{l}\mathrm{CISH} / \\
\mathrm{FISH}\end{array}$ & $\begin{array}{l}\text { Large gene copy cluster } \\
\text { in }>50 \% \text { cells or }>10 \\
\text { separate gene copies }\end{array}$ & 3.8 & $\begin{array}{l}\text { Yes - poorer } \\
\text { survival }\end{array}$ \\
\hline $\begin{array}{l}\text { Gravalos } \\
\text { et } \mathrm{al}^{42}\end{array}$ & 126 & Spain & Surgical & 115 & 11 & $\begin{array}{l}\mathrm{FISH} / \\
\mathrm{IHC}\end{array}$ & $\begin{array}{l}\text { FISH+ and IHC 2+ } \\
\text { or IHC 3+ }\end{array}$ & 13.5 & NS \\
\hline $\begin{array}{l}\text { Tanner } \\
\text { et al }\left.\right|^{43}\end{array}$ & 231 & Finland & $\begin{array}{l}\text { Biopsy, } \\
\text { surgical }\end{array}$ & NS & NS & $\mathrm{CISH}$ & $\mathrm{ClSH}+/ \mathrm{CISH}-$ & 17.3 & $\begin{array}{l}\text { Yes-poorer } \\
\text { survival }\end{array}$ \\
\hline $\begin{array}{l}\text { Nakajima } \\
\text { et al }{ }^{39}\end{array}$ & 128 & Japan & Surgical & NS & NS & $\begin{array}{l}\text { Southern } \\
\text { blot }\end{array}$ & $\begin{array}{l}\geq 2 \times \text { amount in normal } \\
\text { gastric mucosa }\end{array}$ & 11.7 & $\begin{array}{l}\text { Yes-poorer } \\
\text { survival }\end{array}$ \\
\hline $\begin{array}{l}\text { Ishikawa } \\
\text { et } \text { al }^{40}\end{array}$ & 105 & Japan & Surgical & NS & NS & FISH & $\begin{array}{l}\text { HER2 amplification } \\
\text { in }>28 \% \text { cells of tumor } \\
\text { specimen }\end{array}$ & 18.1 & NS \\
\hline
\end{tabular}

Abbreviations: CEP-17, chromosome 17 centromere; $\mathrm{CISH}$, chromogenic in situ hybridization; FISH, fluorescence in situ hybridization; HER2, human epidermal growth factor receptor 2; IHC, immunohistochemistry; NS, not stated; TOP2A, topoisomerase-ll $\alpha$ (co-amplified with HER2).

associated HER2 overexpression or over-amplification with poorer outcomes, but this finding has not been a consistent one. A recent systematic review consisting of 12,749 patients from 42 publications was conducted by Jørgensen and Hersom, who investigated the prognostic significance of HER2 status in patients with GC. In 30 of 42 publications, HER2 overexpression or amplification was associated with poorer survival outcomes and negative clinicopathologic features, such as advanced local invasion, lymph node metastases, distant metastases, and advanced tumor stage. ${ }^{44}$

While there appears to be a trend toward HER2 overexpression or over-amplification as a negative prognostic factor, this finding must be read with caution. In critically analyzing the prognostic significance of tumor markers, it is essential to bear in mind that conflicting results between studies may be the result of nonstandardized methods of marker study and differences in the limits used to determine HER2 positivity. This is particularly true of IHC studies that may have used parameters applicable to breast lesions but not necessarily
GCs, in which HER2-positive samples are more likely to exhibit non-circumferential, heterogeneous staining that would preclude $3+$ or $2+$ scoring under the algorithm used for breast cancers. ${ }^{34}$ Certainly, the overall data on HER2 as a prognostic factor is not as consistent as the current available data on its role in breast cancer. Finally, the presence of publication bias may obscure the results of systematic reviews, because studies demonstrating no association are unlikely to have been published.

\section{Possible therapeutic implications of HER2 \\ Preclinical studies of trastuzumab}

Trastuzumab is a humanized monoclonal anti-HER 2 antibody that has been approved in the management of HER2-positive metastatic breast cancer for over a decade. A selective inhibitor of the HER2 receptor, trastuzumab is composed of two antigen-specific sites and a humanized Fc portion. While its mechanisms of action have not been entirely elucidated, it is 
Table 3 Literature survey of trials of trastuzumab for locally advanced or metastatic gastric cancer

\begin{tabular}{|c|c|c|c|c|c|c|c|c|c|c|}
\hline Group & $\mathbf{n}$ & Phase & Line & Stage & $\begin{array}{l}\text { HER2 testing } \\
\text { method }\end{array}$ & Schedule & $\begin{array}{l}\text { ORR } \\
\text { (\%) }\end{array}$ & $\begin{array}{l}\text { OS, months } \\
\text { (median) }\end{array}$ & $\begin{array}{l}\text { TTP, months } \\
\text { (median) }\end{array}$ & $\begin{array}{l}\text { Toxicity } \\
\text { data }\end{array}$ \\
\hline $\begin{array}{l}\text { Bang } \\
\text { et } \mathrm{al}^{4}\end{array}$ & 298 & III & First & III-IV & $\begin{array}{l}\mathrm{FISH}+\mathrm{I} \\
\mathrm{IHC} 2+ \\
\text { or IHC } 3+\end{array}$ & $\begin{array}{l}\text { 3-week cycle, } 6 \text { cycles: } \\
\text { - capecitabine I,000 mg/m² } \\
\text { bd for I4 days or IV 5-FU } \\
800 \mathrm{mg} / \mathrm{m}^{2} \text { days I-5 } \\
\text { - cisplatin } 80 \mathrm{mg} / \mathrm{m}^{2} \text { day I } \\
\text { - trastuzumab } 6 \mathrm{mg} / \mathrm{kg} \text { day } \\
\text { I }(8 \mathrm{mg} / \mathrm{kg} \text { first cycle) }\end{array}$ & 47.3 & 13.8 & 7.1 & $\begin{array}{l}68 \% \\
\text { grade III } \\
\text { or IV }\end{array}$ \\
\hline $\begin{array}{l}\text { Grávalos } \\
\text { et } \mathrm{al}^{48}\end{array}$ & 22 & II & First & III-IV & $\begin{array}{l}\mathrm{FISH}+/ \\
\mathrm{IHC} 2+ \\
\text { or IHC 3+ }\end{array}$ & $\begin{array}{l}\text { 3-week cycle: } \\
\text { - cisplatin } 75 \mathrm{mg} / \mathrm{m}^{2} \text { day I } \\
\text { - trastuzumab } 6 \mathrm{mg} / \mathrm{kg} \text { day } \\
\text { I }(8 \mathrm{mg} / \mathrm{kg} \text { first cycle) }\end{array}$ & 31.8 & 12.9 & 5.1 & $\begin{array}{l}\text { No grade } \\
\text { IV }\end{array}$ \\
\hline $\begin{array}{l}\text { Nicholas } \\
\text { et } \mathrm{al}^{50}\end{array}$ & 5 & II & First & IV & $\begin{array}{l}\mathrm{FISH}+ \\
\text { or IHC 3+ }\end{array}$ & $\begin{array}{l}\text { 3-week cycle: } \\
\text { - cisplatin } 75 \mathrm{mg} / \mathrm{m}^{2} \text { day I } \\
\text { - docetaxel } 75 \mathrm{mg} / \mathrm{m}^{2} \text { day I } \\
\text { - trastuzumab } 6 \mathrm{mg} / \mathrm{kg} \text { day } \\
\text { I }(8 \mathrm{mg} / \mathrm{kg} \text { first cycle })\end{array}$ & 80.0 & - & - & - \\
\hline
\end{tabular}

Abbreviations: bd, twice daily; FISH, fluorescence in situ hybridization; HER2, human epidermal growth factor receptor 2; IHC, immunohistochemistry; IV, intravenous; MFU, median follow-up; ORR, overall response rate; OS, overall survival; TTP, time to progression; 5-FU, 5-fluorouracil.

thought to demonstrate anti-tumor effects through 1) competitive inhibition of the extracellular domain of HER2 and prevention of HER2-dependent dimerization; 2) activation of immune-effector cells via its Fc portion, promoting cell-mediated cytotoxicity; and 3) resultant downregulation of HER2 receptors on the surface of malignant cells. ${ }^{45}$

Initial data from preclinical studies provided encouraging evidence of the anti-tumorigenic effects of anti-HER2 therapy in GC. The first study that investigated the effect of inhibiting HER2 in human GC lines was conducted in 1992 by Kasprzyk et al, who demonstrated that the injection of two monoclonal anti-HER2 antibodies inhibited the in vitro growth of the NCI-N87 cell line within nude mice. ${ }^{46}$ Subsequent studies demonstrated the efficacy of trastuzumab alone within in vitro models, including an important study by Tanner et al, who compared the sensitivity of N87 and SKBR-3, a breast cancer cell line, to trastuzumab. The study concluded that trastuzumab was equally effective in inhibiting the growth of GC and breast cancer cells overexpressing HER2. ${ }^{43}$ Recent data suggest that this inhibition may be improved when trastuzumab is used in combination with a variety of chemotherapeutic agents. This was most convincingly demonstrated in a study conducted by Fujimoto-Ouchi et al, who investigated the anti-tumor activity of various chemotherapy regimens within xenografts of NCI-N87 within murine models. The most effective regime against GC appeared to be a combination of capecitabine, cisplatin, and trastuzumab, the combination used later in the ToGA trial. ${ }^{4,47}$

Subsequent Phase II trials demonstrated the clinical safety and potential efficacy of trastuzumab in human patients, limited to the setting of inoperable, locally advanced or mGC (see Table 3). A trial by Grávalos et al, completed in 2011, studied the use of trastuzumab in combination with cisplatin for treatment-naïve patients with FISH+/IHC 2+ or IHC 3+ stage III-IV GC. They found an overall response (partial or complete) rate of $31.8 \%$, with a median overall survival of 12.9 months, median time to progression of 5.1 months, and no grade IV adverse events. ${ }^{48}$ The results of these preliminary studies provided a rationale to evaluate the efficacy of trastuzumab in the setting of a randomized controlled trial.

\section{The ToGA trial}

The ToGA study (NCT01041404) was an international, open-label, multicenter Phase III trial that investigated the use of trastuzumab for HER2-positive advanced GC or gastroesophageal cancer (see Table 3). ${ }^{4}$ Initially, 3,803 patients were assessed for eligibility via IHC HER2 testing (HercepTest ${ }^{\mathrm{TM}}$; Dako, Glostrup, Denmark) and FISH (HER2 FISH pharmDx ${ }^{\mathrm{TM}}$; Dako), where HER2 overexpression and amplification were defined as IHC $3+$ or FISH+ (HER2/ CEP-17 ratio $\geq 2$ ). In total, the study consisted of a total of 594 patients from 122 centers, of whom 298 were assigned trastuzumab plus chemotherapy, either 5-FU or capecitabine with cisplatin ( $\mathrm{n}=298)$, and 296 received such chemotherapy alone $(n=296)$. Chemotherapy was administered every 3 weeks for six cycles, and clinicians had a choice between capecitabine $1,000 \mathrm{mg} / \mathrm{m}^{2}$ orally twice daily for 14 days followed by 7 -day rest or IV 5 -FU $800 \mathrm{mg} / \mathrm{m}^{2}$ per day on days $1-5$ on each cycle with $80 \mathrm{mg} / \mathrm{m}^{2}$ cisplatin on day 1 of the first cycle. IV trastuzumab was administered at a loading dose of 
$8 \mathrm{mg} / \mathrm{kg}$, proceeded by $6 \mathrm{mg} / \mathrm{kg}$ every third week until disease progression, major toxicity, or withdrawal of consent.

With a median follow-up of 17.1 months, the trial found a statistically significant difference in median survival between individuals receiving additional trastuzumab compared to patients placed on standard chemotherapy (median survival 13.8 months versus 11.1 months, respectively, $P=0.0046$ ). Compared to patients placed on standard chemotherapy alone, patients who received additional trastuzumab had longer progression-free survival (6.7 months versus 5.5 months, $P=0.0002)$, time to progression ( 7.1 months versus 5.6 months, $P=0.0003$ ), duration of response to therapy (6.9 months versus 4.8 months, $P<0.0001$ ), and higher overall tumor response rate ( $47 \%$ versus $35 \%, P=0.00175$ ). A tolerability study by the investigators found that the addition of trastuzumab did not increase the toxic adverse effects seen in patients administered standard fluoropyrimidine- and platinum-based chemotherapy.

While the results of the addition of trastuzumab to standard chemotherapy appeared to provide only a modest improvement in overall survival for patients with $\mathrm{mGC}$, it should be noted that this improvement was most pronounced in a subset analysis of 446 patients with high expression of HER2 (IHC $2+$ FISH+ or IHC $3+$ tumors) confirmed on post hoc analysis. In these patients, those administered additional trastuzumab had a median survival of 16.0 months compared to 11.8 months in patients without (HR 0.65, 95\% CI: 0.51-0.83). Conversely, in 131 patients with low expression of HER2 (IHC 0 or 1+/FISH+), additional trastuzumab did not appear to confer a statistically significant improvement in survival (median survival 10.0 months versus 8.7 months, HR 1.07, 95\% CI: $0.70-1.62) .{ }^{4}$ This result has two major implications: firstly, the addition of trastuzumab appears to provide the greatest benefit for strongly HER2-positive disease. Secondly, unlike breast cancer, for which FISH is the gold standard in determining HER2 status ${ }^{49}$ these results from the ToGA trial may suggest that IHC may be preferable to FISH in screening patient eligibility for HER2-targeted therapy.

There were several limitations of the ToGA trial. Firstly, the results were not stratified according to the site of gastric origin or staging, so it is unclear if these factors have predictive value for patients treated with HER2-targeted therapy. In the study, the majority of patients (96.6\%) had metastatic disease, and the efficacy of trastuzumab was established in these patients (HR $0.73,95 \%$ CI: $0.59-0.90$ ). In the 20 patients with locally advanced disease, the addition of trastuzumab did not appear to improve survival (HR 1.20, 95\% CI: 0.29-4.97); however, this sample is too small to determine whether trastuzumab is effective in nonmetastatic GC. It is also unclear whether trastuzumab in combination with standard chemotherapy is effective in the adjuvant setting after previous gastrectomy. In the trial, there were 133 patients enrolled who had undergone previous gastrectomy, and no significant differences were found between the two treatment regimes. While it is plausible that trastuzumab may be effective in resectable GC due to decreased tumor volume, this must be confirmed in trials exploring the potential role of trastuzumab in an adjuvant setting. Finally, a significant limitation of all clinical trials that rely on biomarker assessment is that the efficacy of various therapies based on receptor over-amplification or overexpression may differ with technique and calibration.

\section{Current guidelines for HER2 testing}

Precise and accurate determination of HER2 positivity is vital in determining appropriate candidates for HER2-targeted therapy. This was evident from the ToGA trial, in which patients who were IHC 0 or $1+$ and FISH+ did not achieve a statistically significant improvement in survival when placed on additional trastuzumab. Moreover, the overall response rate in this group was $47 \%$, which suggests that the limitations of the HER 2 scoring system used by the trial, then still in its infancy, may have led to the enrollment of false positives or the exclusion of false negatives in the study. ${ }^{4}$

An initial development in the formulation of a HER2 scoring system was made by Hofmann et al, who studied the HER2 status of 168 resected specimens of gastric $(n=149)$, gastroesophageal $(n=16)$, and esophageal $(n=3)$ tumors via IHC and FISH. In determining HER2 status, the concordance between IHC and FISH was 93.5\% $;{ }^{34}$ however, eleven (6.5\%) samples were scored as FISH+ but IHC - or equivocal, revealing important differences in patterns of staining between breast cancer and GC: firstly, while circumferential membrane staining is a prerequisite for $2+$ or $3+$ staining in breast cancer, lateral or basolateral staining is sufficient for GCs; secondly, in contrast to breast lesions, which often stain homogeneously, GCs frequently stain heterogeneously and, therefore, a threshold of $10 \%$ of cells with positive staining was deemed appropriate to assess HER2 status, compared to $30 \%$ for breast tumors.

Despite these findings, considerable debate remains regarding the most accurate system to determine HER2 status. The European Medicines Agency has recently recommended IHC as the initial screening test for all prospective patients, with $3+$ samples considered positive and all $2+$ samples positive if confirmed by FISH analysis. ${ }^{51} \mathrm{By}$ contrast, the FDA has recommended the eligibility criteria used by 
the ToGA trial, in which HER2-positive samples are either IHC $3+$ or FISH+. ${ }^{52}$ It is anticipated that the publication of future trials of trastuzumab and the stratification of results according to findings on IHC/FISH will clarify the limits that should be used to determine HER2 expression.

\section{The future of HER2-targeted therapy in GC}

The findings of the ToGA trial have led to a recent surge in trials evaluating other HER2-targeted therapies for locally advanced or $\mathrm{mGC}$.

\section{Lapatinib}

Unlike trastuzumab, lapatinib is a dual tyrosine kinase inhibitor that inhibits the intracellular domains of both EGFR and HER2, thereby preventing dimerization and intracellular signaling. ${ }^{25}$ Lapatinib has been approved for use in combination with capecitabine for the management of HER2positive, locally advanced, or metastatic breast cancer, ${ }^{53}$ and is currently being investigated for GC. The Lapatinib in combination with capecitabine plus oxaliplatin (CapeOx) in HER2-positive advanced or metastatic gastric, esophageal, or gastroesophageal adenocarcinoma (AC), TRIO-013/ LOGiC (NCT00680901) trial is a concluding international, multicenter, double-blinded study that investigated the use of lapatinib ditosylate in combination with capecitabine and oxaliplatin (CAPOX) for the treatment of gastric, esophageal, or gastroesophageal adenocarcinomas. ${ }^{54}$ In total, 545 patients with HER2 overexpression or over-amplification were randomized to either CAPOX with lapatinib $(\mathrm{CAPOX}+\mathrm{L})$ or placebo. The preliminary findings of this trial were recently presented at the 2013 ASCO Annual Meeting, ${ }^{54}$ where the median overall survival and progression-free survival for the CAPOX+L group were 12.2 and 6 months, respectively, compared to 10.5 and 5.4 months for the control. While these modest improvements for the overall study population were not statistically significant, subgroup analysis revealed significant improvements for Asian patients and patients under 60 years. The trial's final results are needed to confirm these findings.

\section{Pertuzumab}

Pertuzumab is a monoclonal antibody that prevents the heterodimerization of HER2 with other EGFRs. ${ }^{25}$ A recent Phase II trial by Baselga et al has demonstrated its efficacy in improving outcomes in patients with metastatic breast cancer who had progressed on trastuzumab-based chemotherapy. ${ }^{55}$ Currently, there is an active double-blind, placebo-controlled randomized clinical trial in which patients will be randomized to receive pertuzumab $(840 \mathrm{mg}$ ) or placebo in combination with trastuzumab (loading dose $8 \mathrm{mg} / \mathrm{kg}$, followed by $6 \mathrm{mg} / \mathrm{kg}$ every 3 weeks), cisplatin, and capecitabine or 5-FU for six cycles. ${ }^{56}$

\section{Trastuzumab emtansine (T-DMI)}

T-DM1 is an antibody-drug conjugate composed of trastuzumab and the anti-microtubule agent emtansine, believed to preferentially inhibit HER2-positive cells by binding to HER2 and inducing cell cytotoxicity through the intracellular introduction of emtansine. The agent was recently evaluated in the Trastuzumab Emtansine for HER2-Positive Advanced Breast Cancer (EMILIA) trial (NCT00829166), an international Phase III trial of 991 patients with HER2positive metastatic breast cancer previously treated with trastuzumab and a taxane. Patients were randomized to receive either T-DM1 or lapatinib with capecitabine. ${ }^{57}$ The median survival was 9.6 months compared to 6.4 months, respectively (HR 0.65, 95\% CI: $0.55-0.77, P<0.001$ ). Additionally, T-DM1 was better tolerated and had a lower rate of grade $3 / 4$ adverse events (41\% versus 57\%). Despite these encouraging results, whether T-DM1 is similarly effective in $\mathrm{mGC}$ remains to be seen.

\section{HER2-targeted therapy in the adjuvant setting}

The majority of trials of trastuzumab (and other HER2targeted therapies) have focused solely on patients with locally advanced, unresectable, or metastatic disease; there has been considerable interest, however, in whether trastuzumab may be used in an adjuvant setting after surgical resection of stage II-III disease, particularly in Asia, where patients are more likely to present with earlier, resectable disease due to population-based screening programs. ${ }^{25}$ While multimodal therapy has significantly improved survival in patients with stage II-III disease, the 5-year survival of these patients remains poor. For example, the MAGIC trial demonstrated a 5-year survival of $36.3 \%$, which suggests that the majority of patients will experience recurrence and die from their disease. ${ }^{21}$ This finding may warrant the addition of HER2-targeted therapy such as trastuzumab to future trials of adjuvant therapy in resectable HER2-positive GC.

\section{Conclusion}

Advanced GC and $\mathrm{mGC}$ continue to result in dismal patient outcomes. A landmark evolution in the management of patients with $\mathrm{mGC}$ has been observed in the recent discovery 
of HER2 status as an important predictor of response to the humanized anti-HER2 antibody trastuzumab, renewing the hope that one day it may be possible to individualize and optimize cancer care according to individual tumor biology. Efforts to capitalize on this development will come through the continued refinement of HER2 testing, particularly in delineating the roles of IHC and FISH in selecting candidates eligible for HER2-targeted therapy, as well as future trials investigating their use in combination with a variety of chemotherapeutic regimens in first-line and adjuvant settings for GCs of various stages along with optimal GC surgery.

\section{Disclosure}

The authors report no conflicts of interest in this work.

\section{References}

1. Jemal A, Bray F, Center MM, Ferlay J, Ward E, Forman D. Global cancer statistics. CA: Cancer J Clin. 2011;61(2):69-90.

2. Chua TC, Merrett ND. Clinicopathologic factors associated with HER2-positive gastric cancer and its impact on survival outcomes - a systematic review. Int $J$ Cancer. 2012;130(12):2845-2856.

3. Wagner AD, Unverzagt $\mathrm{S}$, Grothe $\mathrm{W}$, et al. Chemotherapy for advanced gastric cancer. Cochrane Database Syst Rev. 2010;(3):CD004064.

4. Bang YJ, Van Cutsem E, Feyereislova A, et al; ToGA Trial Investigators. Trastuzumab in combination with chemotherapy versus chemotherapy alone for treatment of HER2-positive advanced gastric or gastro-oesophageal junction cancer (ToGA): a phase 3, open-label, randomised controlled trial. Lancet. 2010;376(9742):687-697.

5. Yan B, Yau EX, Bte Omar SS, et al. A study of HER2 gene amplification and protein expression in gastric cancer. J Clin Pathol. 2010;63(9): 839-842.

6. Correa P. Is gastric carcinoma an infectious disease? $N$ Engl $J$ Med. 1991;325(16):1170-1171.

7. Hanahan D, Weinberg RA. The hallmarks of cancer. Cell. 2000;100(1): $57-70$.

8. Kelley JR, Duggan JM. Gastric cancer epidemiology and risk factors. J Clin Epidemiol. 2003;56(1):1-9.

9. Houghton J, Wang TC. Helicobacter pylori and gastric cancer: a new paradigm for inflammation-associated epithelial cancers. Gastroenterology. 2005;128(6):1567-1578.

10. Huang JQ, Sridhar S, Chen Y, Hunt RH. Meta-analysis of the relationship between Helicobacter pylori seropositivity and gastric cancer. Gastroenterology. 1998;114:1169-1179.

11. Uemura N, Okamoto S, Yamamoto S, et al. Helicobacter pylori infection and the development of gastric cancer. $N$ Engl J Med. 2001;345(11): 784-789.

12. Wu CY, Kuo KN, Wu MS, Chen YJ, Wang CB, Lin JT. Early Helicobacter pylori eradication decreases risk of gastric cancer in patients with peptic ulcer disease. Gastroenterology. 2009;137(5): 1641-1648. e1-2.

13. Ernst P. Review article: the role of inflammation in the pathogenesis of gastric cancer. Aliment Pharmacol Ther. 1999;13 Suppl 1:13-18.

14. Leung WK, Yu J, Ng EK, et al. Concurrent hypermethylation of multiple tumor-related genes in gastric carcinoma and adjacent normal tissues. Cancer. 2001;91(12):2294-2301.

15. Houghton J, Stoicov C, Nomura S, et al. Gastric cancer originating from bone marrow-derived cells. Science. 2004;306(5701):1568-1571.

16. Green PH, O'Toole KM, Slonim D, Wang T, Weg A. Increasing incidence and excellent survival of patients with early gastric cancer: experience in a United States medical center. Am J Med. 1988;85(5):658-661.

17. Hayashida T, Kidokoro T. End results of early gastric cancer collected from 22 institutions. Stomach and Intestine. 1969;4:1077.
18. Smalley SR, Benedetti JK, Haller DG, et al. Updated analysis of SWOG-directed intergroup study 0116: a phase III trial of adjuvant radiochemotherapy versus observation after curative gastric cancer resection. J Clin Oncol. 2012;30(19):2327-2333.

19. Macdonald JS, Smalley SR, Benedetti J, et al. Chemoradiotherapy after surgery compared with surgery alone for adenocarcinoma of the stomach or gastroesophageal junction. $N$ Engl J Med. 2001;345(10): 725-730.

20. Lee J, Lim do H, Kim S, et al. Phase III trial comparing capecitabine plus cisplatin versus capecitabine plus cisplatin with concurrent capecitabine radiotherapy in completely resected gastric cancer with $\mathrm{D} 2$ lymph node dissection: the ARTIST trial. J Clin Oncol. 2012;30(3):268-273.

21. Cunningham D, Allum WH, Stenning SP, et al. Perioperative chemotherapy versus surgery alone for resectable gastroesophageal cancer. N Engl J Med. 2006;355(1):11-20.

22. Ychou M, Boige V, Pignon JP, et al. Perioperative chemotherapy compared with surgery alone for resectable gastroesophageal adenocarcinoma: an FNCLCC and FFCD multicenter phase III trial. $J$ Clin Oncol. 2011;29(13):1715-1721.

23. Sakuramoto S, Sasako M, Yamaguchi T, et al. Adjuvant chemotherapy for gastric cancer with S-1, an oral fluoropyrimidine. $N$ Engl J Med. 2007;357(18):1810-1820.

24. Bang YJ, Kim YW, Yang HK, et al; CLASSIC trial investigators. Adjuvant capecitabine and oxaliplatin for gastric cancer after D2 gastrectomy (CLASSIC): a phase 3 open-label, randomised controlled trial. Lancet. 2012;379(9813):315-321.

25. Bang YJ. Advances in the management of HER2-positive advanced gastric and gastroesophageal junction cancer. J Clin Gastroenterol. 2012;46(8):637-648.

26. Kang YK, Kang WK, Shin DB, et al. Capecitabine/cisplatin versus 5 -fluorouracil/cisplatin as first-line therapy in patients with advanced gastric cancer: a randomised phase III noninferiority trial. Ann Oncol. 2009;20(4):666-673.

27. Cunningham D, Starling N, Rao S, et al. Capecitabine and oxaliplatin for advanced esophagogastric cancer. N Engl J Med. 2008;358(1): 36-46.

28. Yarden Y, Sliwkowski MX. Untangling the ErbB signalling network. Nat Rev Mol Cell Biol. 2001;2(2):127-137.

29. Olayioye MA, Neve RM, Lane HA, Hynes NE. The ErbB signaling network: receptor heterodimerization in development and cancer. $E M B O$ J. 2000;19(13):3159-3167.

30. Ménard S, Pupa SM, Campiglio M, Tagliabue E. Biologic and therapeutic role of HER2 in cancer. Oncogene. 2003;22:6570-6578.

31. Sakai K, Mori S, Kawamoto T, et al. Expression of epidermal growth factor receptors on normal human gastric epithelia and gastric carcinomas. J Natl Cancer Inst. 1986;77(5):1047-1052.

32. Kim MA, Lee HJ, Yang HK, Bang YJ, Kim WH. Heterogeneous amplification of ERBB2 in primary lesions is responsible for the discordant ERBB2 status of primary and metastatic lesions in gastric carcinoma. Histopathology. 2011;59(5):822-831.

33. Marx AH, Tharun L, Muth J, et al. HER-2 amplification is highly homogenous in gastric cancer. Hum Pathol. 2009;40(6):769-777.

34. Hofmann M, Stoss O, Shi D, et al. Assessment of a HER2 scoring system for gastric cancer: results from a validation study. Histopathology. 2008;52(7):797-805.

35. Kim MA, Jung EJ, Lee HS, et al. Evaluation of HER-2 gene status in gastric carcinoma using immunohistochemistry, fluorescence in situ hybridization, and real-time quantitative polymerase chain reaction. Hum Pathol. 2007;38(9):1386-1393.

36. Park DI, Yun JW, Park JH, et al. HER-2/neu amplification is an independent prognostic factor in gastric cancer. Dig Dis Sci. 2006;51(8): 1371-1379.

37. Yano T, Doi T, Ohtsu A, et al. Comparison of HER2 gene amplification assessed by fluorescence in situ hybridization and HER2 protein expression assessed by immunohistochemistry in gastric cancer. Oncol Rep. 2006;15(1):65-71.

38. Allgayer H, Babic R, Gruetzner KU, Tarabichi A, Schildberg FW, Heiss MM. c-erbB-2 is of independent prognostic relevance in gastric cancer and is associated with the expression of tumor-associated protease systems. J Clin Oncol. 2000;18(11):2201-2209. 
39. Nakajima M, Sawada H, Yamada Y, et al. The prognostic significance of amplification and overexpression of c-met and c-erb B-2 in human gastric carcinomas. Cancer. 1999;85(9):1894-1902.

40. Ishikawa T, Kobayashi M, Mai M, Suzuki T, Ooi A. Amplification of the c-erbB-2 (HER-2/neu) gene in gastric cancer cells. Detection by fluorescence in situ hybridization. Am J Pathol. 1997;151(3):761.

41. Lordick F, Bang Y, Kang Y, et al. 3541 poster HER2-positive advanced gastric cancer: similar HER2-positivity levels to breast cancer. EJC Supplements. 2007;5(4):272.

42. Gravalos C, Marquez A, Colomer R, et al. Correlation between HER2/ neu overexpression/amplification and clinicopathologic parameters in advanced gastric cancer (AGC) patients (pts): a prospective study. Paper presented at: J Clin Oncol (Meeting Abstracts) 2006.

43. Tanner M, Hollmén M, Junttila T, et al. Amplification of HER-2 in gastric carcinoma: association with Topoisomerase II $\alpha$ gene amplification, intestinal type, poor prognosis and sensitivity to trastuzumab. Ann Oncol. 2005;16(2):273-278.

44. Jørgensen JT, Hersom M. HER2 as a prognostic marker in gastric cancer-a systematic analysis of data from the literature. $J$ Cancer. 2012;3:137-144.

45. Hudis CA. Trastuzumab - mechanism of action and use in clinical practice. $N$ Engl J Med. 2007;357(1):39-51.

46. Kasprzyk PG, Song SU, Di Fiore PP, King CR. Therapy of an animal model of human gastric cancer using a combination of anti-erbB-2 monoclonal antibodies. Cancer Res. 1992;52(10):2771-2776.

47. Fujimoto-Ouchi K, Sekiguchi F, Yasuno H, Moriya Y, Mori K, Tanaka Y. Antitumor activity of trastuzumab in combination with chemotherapy in human gastric cancer xenograft models. Cancer Chemother Pharmacol. 2007;59(6):795-805.

48. Grávalos C, Gómez-Martín C, Rivera F, et al. Phase II study of trastuzumab and cisplatin as first-line therapy in patients with HER2-positive advanced gastric or gastroesophageal junction cancer. Clin Transl Oncol. 2011;13(3):179-184.

49. Sauter G, Lee J, Bartlett JM, Slamon DJ, Press MF. Guidelines for human epidermal growth factor receptor 2 testing: biologic and methodologic considerations. J Clin Oncol. 2009;27(8):1323-1333.
50. Nicholas G, Cripps C, Au H-J, et al. Early results of a trial of trastuzumab, cisplatin, and docetaxel (TCD) for the treatment of metastatic gastric cancer over-expressing HER-2. Annals of Oncology. 2006;17(9):316. Abstract 1105.

51. Annex I. Summary of Product Characteristics. European Medicines Agency; 2010. Available from: http:/www.ema.europa.eu/docs/en_GB/ document_library/EPAR_-_Product_Information/human/000278/ WC500074922.pdf. Accessed. September 17, 2013.

52. HERCEPTIN ${ }^{\circledR}$ (trastuzumab) [prescribing information]. San Francisco, CA: Genetech, Inc. Available from: http://www.accessdata.fda.gov/drugsatfda_docs/label/2010/103792s52501bl.pdf. Accessed September 17, 2013.

53. Geyer CE, Forster J, Lindquist D, et al. Lapatinib plus capecitabine for HER2-positive advanced breast cancer. N Engl J Med. 2006;355(26): 2733-2743.

54. Hecht R, Bang Y-J, Qin S, et al. Lapatinib in combination with capecitabine plus oxaliplatin (CapeOx) in HER2-positive advanced or metastatic gastric, esophageal, or gastroesophageal adenocarcinoma (AC): The TRIO-013/LOGiC Trial. American Society of Clinical Oncology (ASCO); 2013. Available from: http://meetinglibrary.asco. org/content/116873-132. Accessed September 17, 2013.

55. Baselga J, Gelmon KA, Verma S, et al. Phase II trial of pertuzumab and trastuzumab in patients with human epidermal growth factor receptor 2-positive metastatic breast cancer that progressed during prior trastuzumab therapy. J Clin Oncol. 2010;28(7):1138-1144.

56. Hoffmann-La Roche. A study of Perjeta (pertuzumab) in combination With Herceptin (trastuzumab) and chemotherapy in patients with HER2-positive metastatic gastroesophageal junction or gastric cancer. Available from: http://www.clinicaltrials.gov/show/NCT01774786. NLM identifier: NCT01774786. Accessed September 17, 2013.

57. Verma S, Miles D, Gianni L, et al; MILIA Study Group. Trastuzumab emtansine for HER2-positive advanced breast cancer. $N$ Engl J Med. 2012;367(19):1783-1791
Gastrointestinal Cancer: Targets and Therapy

\section{Publish your work in this journal}

Gastrointestinal Cancer: Targets and Therapy is an international, peer-reviewed, open access journal focusing on gastro-intestinal cancer research, identification of therapeutic targets and the optimal use of preventative and integrated treatment interventions to achieve improved outcomes, enhanced survival and quality of life for the

\section{Dovepress}

cancer patient. The manuscript management system is completely online and includes a very quick and fair peer-review system. Visit http://www.dovepress.com/testimonials.php to read real quotes from published authors. 